\title{
Measuring moisture content in building materials with Time-Domain Reflectometry: pros, cons and first results
}

\author{
Teresa Stingl Freitas ${ }^{\mathrm{a}}$, Ana Sofia Guimarães ${ }^{\mathrm{a}}$, Staf Roels $^{\mathrm{b}}$, Vasco Peixoto de Freitas $^{\mathrm{a}}$, Andrea Cataldo $^{\mathrm{c}}$ \\ ${ }^{a}$ Construct- LFC, Faculty of Engineering University of Porto, R. Dr. Roberto Frias, 4200-465 Porto, Portugal \\ ${ }^{b}$ KU Leuven, Department of Civil Engineering, Building Physics and Sustainable Design, Kasteelpark Arenberg 40 Bus 2447,3001 Heverlee, Belgium \\ ${ }^{c}$ Department of Innovation Engineering, University of Salento, Via Monteroni, 73100 Lecce, Italy.
}

\begin{abstract}
Measuring moisture content in construction materials is extremely important both for professional practice as well as for research. However, this is a very complex task, especially when long-term minor destructive measurements are desired. The time-domain reflectometry (TDR) technique is frequently used for soil moisture measurements, but its application in construction materials is considered a relatively new method, particularly for low-porosity building materials. In this paper, the challenges of using the TDR technique for moisture content measurement in construction materials, as well as its major advantages are discussed. In addition, the TDR method was tested in two different materials: limestone and solid brick. The obtained results suggest that the TDR technique is suitable for moisture content measurements in both materials, encouraging future applications and further developments.

Peer-review under the responsibility of the organizing committee of the ICMB21.
\end{abstract}

Keywords: Moisture measurement; TDR; calibration; limestone; solid brick

\begin{tabular}{|c|c|}
\hline Nom & lature \\
\hline$\varepsilon_{a p p}$ & Apparent relative dielectric permittivity $[-]$ \\
\hline W & Moisture content $\left[\mathrm{kg} / \mathrm{m}^{3}\right]$ \\
\hline
\end{tabular}

\section{Introduction}

There is a wide variety of techniques available for moisture content determination. In practice, often non-destructive techniques are used, but they only provide surface moisture content measurements. To fully characterize the moisture content distribution in a construction element, material sampling is required, and as a consequence successive measurements cannot be repeated at the same point. Furthermore, many common moisture methods can only be employed in the laboratory and are not suitable to be used on-site, due to the requirements of the equipment involved, as happens with the nuclear magnetic resonance method (NMR) or with the radiation attenuation techniques, such as X-ray, neutron absorption, and $\gamma$-ray attenuation method [1]. The TDR technique can be seen as a solution to overcome these limitations, since it allows continuous long-term minor destructive monitoring of moisture contents in the study element, in-depth and with a portable equipment. However, there is scarce information about its performance in hard low-porosity building materials. In addition, the lack of appropriate conversion functions between the direct output of the TDR technique, the apparent relative dielectric permittivity $\left(\varepsilon_{\text {app}}\right.$ ), and the moisture content of building materials (W) is commonly recognized as one of the major obstacles to its current use in construction materials. Indeed, the empirical conversion functions proposed for soils are mostly not suitable for building materials and there is no standardize calibration procedure to obtain appropriate conversion functions, $\mathrm{W}\left(\varepsilon_{\mathrm{app}}\right)$, for construction materials.

\section{TDR application in construction materials}

In this paper, the TDR technique was applied in small samples of limestone and solid brick. The main purpose was to test the suitability of the technique to detect moisture content variations in these materials and to present a calibration process, suitable for construction materials, using the gravimetric method as a reference. Figure 1 shows, as an example, the used limestone sample and Figure 2 the main steps followed during the gravimetric calibration. The same procedure was followed for the solid brick.
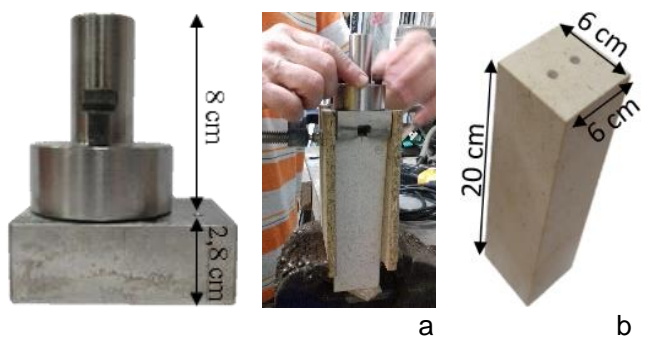

b

Figure 1. Sample preparation: a) steel auxiliary guide; (b) final drilled limestone sample.
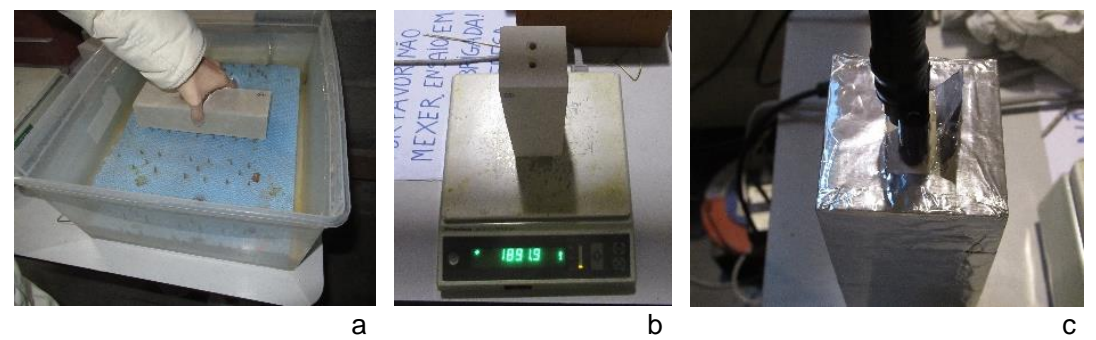

Figure 2. Gravimetric calibration steps: (a) water immersion; (b) sample weighing; (c) TDR measurement after moisture content redistribution in the completely waterproofed sample. 


\section{Results and discussion}

Table 1 shows the relation between the moisture content measured gravimetrically and the apparent relative dielectric permittivity obtained for limestone and solid brick, and Figure 3 shows the respective reflectograms. A detailed description of the reflectograms' definition and how the $\varepsilon_{\text {app }}$ value is obtained through them can be found in [2]. The results reveal that the TDR technique is suitable to detect moisture content variations in both materials. However, the difference between the $\varepsilon_{\text {app }}$ value for the dry and saturated limestone is lower than the one obtained for solid brick (Table 1). This is mainly due to the inferior porosity of limestone. Indeed, the performance of the TDR technique for low-porosity building materials has greater challenges than for highporosity building elements, because the technique may be poorly sensitive to detect smaller moisture content variations. That is why most of the TDR applications in construction materials refer to highly porous building elements, such as gypsum or calcium silicate [3]. In spite of that, the results obtained for limestone proved that the technique is capable of detecting even small moisture content variations $\left(\Delta \varepsilon_{\mathrm{app}}=0.6\right.$ for $\left.\Delta \mathrm{W}=14.5 \mathrm{~kg} / \mathrm{m}^{3}\right)$.

Table 1. Relation between the moisture content measured gravimetrically and the apparent relative dielectric permittivity for limestone and solid brick.

\begin{tabular}{|c|c|c|c|c|c|c|}
\hline & \multicolumn{3}{|c|}{ Limestone $\left(\right.$ sample volume $\left.=0.0007332844 \mathrm{~m}^{3}\right)$} & \multicolumn{3}{|c|}{ Solid brick (sample volume $=0.0016449091 \mathrm{~m}^{3}$ ) } \\
\hline & Sample mass $(\mathrm{kg})$ & $\mathrm{W}\left(\mathrm{kg} / \mathrm{m}^{3}\right)$ & $\varepsilon_{a p p}(-)$ & Sample mass $(\mathrm{kg})$ & $\mathrm{W}\left(\mathrm{kg} / \mathrm{m}^{3}\right)$ & $\varepsilon_{a p p}(-)$ \\
\hline Dry in oven & 1.8917 & 0 & 6.8 & 3.3748 & 0 & 3.2 \\
\hline Moist & 1.9023 & 14.5 & 7.4 & 3.5209 & 88.8 & 5.4 \\
\hline Saturated & 1.9146 & 31.2 & 8.4 & 3.6403 & 161.4 & 8.9 \\
\hline
\end{tabular}
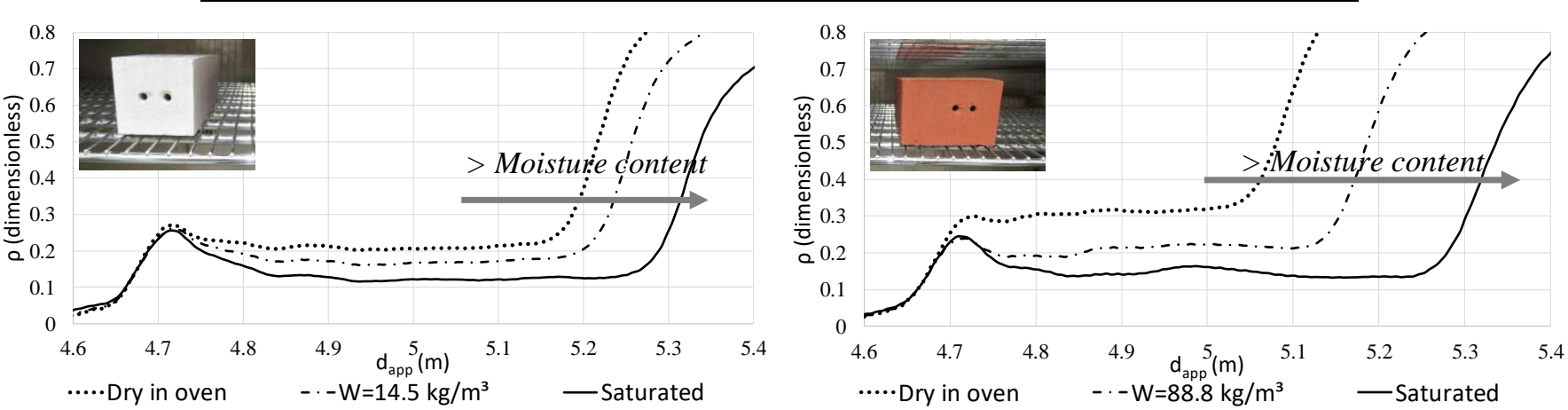

Figure 3. TDR reflectograms acquired for different moisture content values: (a) limestone; (b) solid brick.

In the near future, the relation between $\mathrm{W}$ and $\varepsilon_{\text {app }}$ will be established for more points than the ones presented in Table 1 , in order to adjust a calibration function for limestone and solid brick. In addition, the calibration process will be repeated for different samples to evaluate the reproducibility of the results. This task is especially important since the quality of the TDR measurements is strongly influenced by the contact between the probe and the material. Any air gap present between the probes' rods and the material will compromise the measurements, which complicates the probes' installation process. Indeed, drilling regular holes without producing large air gaps can be a challenge for hard materials. Therefore, this reiteration is useful to validate and obtain more robust results, particularly for low-porosity building materials, where the sensitivity range of the TDR technique is smaller.

\section{Conclusions}

Monitoring moisture content in building materials is a complex subject, which is still the focus of ongoing research. Despite the wide use of the TDR technique for moisture content measurements in soils, its application in construction materials still faces many challenges. The lack of appropriate conversion functions between the measured $\varepsilon_{\text {app }}$ values and the moisture content for building materials, $\mathrm{W}\left(\varepsilon_{\mathrm{app}}\right)$, is one of the biggest. Indeed, the experimental determination of these conversion functions through the proposed gravimetric method is a very time-consuming task, since the moisture content needs to redistribute and become homogenous in the sample to obtain a valid relation between $\mathrm{W}$ and $\varepsilon_{\text {app }}$ (Figure $2 \mathrm{c}$ )). However, for a widespread use of the technique in practical engineering applications, a database with several calibration functions for different porosity building materials is required. Only then, the process of measuring the moisture content with the TDR technique would become fast and attractive. Regardless some obstacles, the TDR technique promises to be a minor destructive solution to continuously monitor the moisture content over time, with the advantage of allowing in-situ applications. The good results obtained for limestone and solid brick are very encouraging for the TDR application in other low-porosity building materials and for further developments.

\section{References}

[1] Pinchin, S.E. (2008) Techniques for monitoring moisture in walls, Studies in Conservation, 53, 33-45

[2] Freitas, T.S; Guimarães, A.S.; Roels, S.; de Freitas, V.P.; Cataldo, A. (2020) Is the Time-Domain Reflectometry (TDR) technique suitable for moisture content measurements in low-porosity building materials?, Sustainability,12(19), 7855.

[3] Pavlík, Z.; Mihulka, J.; Fiala, L.; Cerný, R. (2012) Application of Time-Domain reflectometry for measurement of moisture profiles in a drying experiment, International Journal of Thermophysics, 33 (8-9), 1661-1673.

This work was financially supported by Base Funding - UIDB/04708/2020 of the CONSTRUCT — Instituto de I\&D em Estruturas e Construções-funded by national funds through the FCT/MCTES (PIDDAC). The author Teresa Stingl Freitas would also like to thank FCT for financial support through the grant SFRH/BD/121549/2016. 